\title{
Technical Note: Simple analytical relationships between Ångström coefficients of aerosol extinction, scattering, absorption, and single scattering albedo
}

\author{
H. Moosmüller and R. K. Chakrabarty \\ Laboratory for Aerosol Science, Spectroscopy, and Optics, Division of Atmospheric Sciences, Desert Research Institute, \\ Nevada System of Higher Education, Reno, NV 89512, USA
}

Received: 25 May 2011 - Published in Atmos. Chem. Phys. Discuss.: 5 July 2011

Revised: 31 August 2011 - Accepted: 21 October 2011 - Published: 28 October 2011

\begin{abstract}
. Ångström coefficients are commonly used to parameterize the slow wavelength dependence of aerosol scattering, absorption, and extinction coefficients and single scattering albedo. Here we introduce simple analytical relationships between these coefficients that establish a framework for intercomparison between theory and experimental results from different instruments and platforms and allow for closure studies and improved physical understanding.
\end{abstract}

\section{Introduction}

The Ångström coefficient AC was originally introduced as a wavelength-independent constant in a power law to describe wavelength-dependent extinction (or optical depth) of light by aerosols (Ångström, 1929). Since then, it has found additional extensive use in characterizing the "slow" wavelength dependence of scattering, absorption, and single scattering albedo (SSA) (Russell et al., 2010; Fischer et al., 2010; Virkkula et al., 2005; Flowers et al., 2010). ACs are generally not considered appropriate for "fast" wavelength dependences as encountered, for example, in the fast oscillations of scattering coefficients for individual, non-absorbing, spherical particles (Eversole et al., 1993). Symbols used in this paper are summarized in Appendix A.

While simple analytical relationships between extinction, scattering, and absorption coefficients and SSA exist (e.g. Moosmüller et al., 2009), we are not aware of corresponding relationships for ACs. Such relationships are useful to

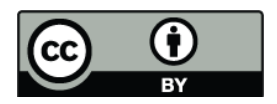

Correspondence to: H. Moosmüller (hansm@dri.edu ) compare ACs obtained from extinction, scattering, and absorption, including the ground truthing of remote sensing and satellite measurements. For example, aerosol optical depth (path-integrated extinction) can be obtained from groundbased and satellite remote sensing at multiple wavelengths yielding extinction Ångström coefficients EACs. Simple analytical relationships between EACs, scattering Ångström coefficients SACs, and absorption Ångström coefficients AACs will help attributing the EACs to the underlying physical phenomena, namely scattering and absorption, and analyzing closure between the different Ångström coefficients. In addition, SSA is the key parameter for obtaining the sign and magnitude of aerosol radiative forcing. SSA can be obtained at multiple wavelengths from in-situ measurements (Lewis et al., 2008; Virkkula et al., 2005; Flowers et al., 2010), ground-based remote sensing measurements (Dubovik et al., 1998; Dubovik and King, 2000), and potentially from satellite measurements (Mishchenko et al., 2007; Zhu et al., 2011). Relating the SSA Ångström coefficient SSAAC to the underlying SAC, AAC, and EAC will help with data interpretation and closure and physical understanding.

Ångström coefficients can be used to express the dependence of any parameter $p(\lambda)$ on wavelength $\lambda$ provided $p(\lambda)$ can be approximated by a power-law function of wavelength. Conventionally, the two-wavelength $\mathrm{AC}$ is used to give the ratio of $p(\lambda)$ at two wavelengths $\lambda_{1}$ and $\lambda_{2}$ as function of the ratio of these wavelengths as (Moosmüller et al., 2009)

$$
\frac{p\left(\lambda_{1}\right)}{p\left(\lambda_{2}\right)}=\left(\frac{\lambda_{1}}{\lambda_{2}}\right)^{-\mathrm{AC}} \text {. }
$$


The AC can be written explicitly as

$\operatorname{AC}\left(\lambda_{1}, \lambda_{2}\right)=-\frac{\ln \left(p\left(\lambda_{1}\right)\right)-\ln \left(p\left(\lambda_{2}\right)\right)}{\ln \left(\lambda_{1}\right)-\ln \left(\lambda_{2}\right)}$,

which is the negative slope of $p(\lambda)$ between wavelengths $\lambda_{1}$ and $\lambda_{2}$ on a log-log plot (Moosmüller et al., 2011). Such a slope obtained at a single wavelength $\lambda$ defines the singlewavelength $\mathrm{AC}(\lambda)$ as (Moosmüller et al., 2011)

$\operatorname{AC}(\lambda)=-\frac{\lambda}{p(\lambda)} \frac{d p(\lambda)}{d \lambda}$.

In addition, ACs can be obtained from simple linear regression of data plotted on a log-log scale or more complicated non-linear fits of data that may also yield higher order terms such as curvature (Schuster et al., 2006). Relationships between different ACs that include the single scattering albedo (SSA) $\omega$ have only been derived by us for single- and twowavelength ACs, while for ACs obtained from linear or nonlinear fits the mathematics gets much more complicated due to the difficulty of appropriately attributing the influence of the SSA at different wavelengths. However, in most cases, the single-wavelength equations still give a good approximation.

In aerosol optics, ACs are of interest for scattering, absorption, and extinction coefficients and for the SSA $\omega$. The relationships between these ACs are investigated using Eq. (1c).

\section{Extinction Ångström coefficient EAC}

The extinction coefficient $\gamma$ is defined as the sum of absorption coefficient $\alpha$ and scattering coefficient $\beta$ as (e.g. Moosmüller et al., 2009),

$\gamma(\lambda)=\alpha(\lambda)+\beta(\lambda)$.

Using Eq. (1c), the extinction Ångström coefficient EAC can be written as

$$
\begin{aligned}
\operatorname{EAC}(\lambda) & =-\frac{\lambda}{\gamma(\lambda)} \frac{d \gamma(\lambda)}{d \lambda}=-\frac{\lambda}{\alpha(\lambda)+\beta(\lambda)} \frac{d(\alpha(\lambda)+\beta(\lambda))}{d \lambda} \\
& =-\frac{\lambda}{\alpha(\lambda)+\beta(\lambda)}\left(\frac{d \alpha(\lambda)}{d \lambda}+\frac{d \beta(\lambda)}{d \lambda}\right) .
\end{aligned}
$$

Rewriting Eq. (1c) for the absorption Ångström coefficient AAC yields (Moosmüller et al., 2011)

$\frac{d \alpha(\lambda)}{d \lambda}=-\frac{\alpha(\lambda)}{\lambda} \operatorname{AAC}(\lambda)$,

with an equivalent expression for the scattering Ångström coefficient SAC

$\frac{d \beta(\lambda)}{d \lambda}=-\frac{\beta(\lambda)}{\lambda} \operatorname{SAC}(\lambda)$.

Substituting Eqs. (2c, d) into Eq. (2b) yields

$$
\begin{aligned}
\operatorname{EAC}(\lambda) & =\frac{\lambda}{\alpha(\lambda)+\beta(\lambda)}\left(\frac{\alpha(\lambda)}{\lambda} \operatorname{AAC}(\lambda)+\frac{\beta(\lambda)}{\lambda} \operatorname{SAC}(\lambda)\right) \\
& =\frac{\beta(\lambda)}{\beta(\lambda)+\alpha(\lambda)}\left(\frac{\alpha(\lambda)}{\beta(\lambda)} \operatorname{AAC}(\lambda)+\operatorname{SAC}(\lambda)\right) .
\end{aligned}
$$

With the SSA $\omega(\lambda)$ defined as

$\omega(\lambda)=\frac{\beta(\lambda)}{\beta(\lambda)+\alpha(\lambda)}$,

and the single scattering co-albedo (SSCA) $\varpi(\lambda)$ defined as

$\varpi(\lambda)=1-\omega(\lambda)=\frac{\alpha(\lambda)}{\alpha(\lambda)+\beta(\lambda)}$,

Eq. (2e) can be written as

$$
\begin{aligned}
\operatorname{EAC}(\lambda) & =\omega(\lambda)\left[\left(\frac{1}{\omega(\lambda)}-1\right) \operatorname{AAC}(\lambda)+\operatorname{SAC}(\lambda)\right] \\
& =\operatorname{AAC}(\lambda)+\omega(\lambda)[\operatorname{SAC}(\lambda)-\operatorname{AAC}(\lambda)] \\
& =\varpi(\lambda) \operatorname{AAC}(\lambda)+\omega(\lambda) \operatorname{SAC}(\lambda),
\end{aligned}
$$

where the extinction Ångström coefficient EAC is the sum of the $\varpi$-weighted absorption Ångström coefficient AAC, and the $\omega$-weighted scattering Ångström coefficient SAC. As expected, the EAC is dominated by the AAC for mostly absorbing (i.e. black, $\varpi \approx 1$ ) particles and by the SAC for mostly scattering (i.e. white, $\omega \approx 1$ ) particles.

Simple examples for specific cases include (a) if $\operatorname{AAC}(\lambda)$ $=\operatorname{SAC}(\lambda)$, the $\operatorname{EAC}$ can be written as $\operatorname{EAC}(\lambda)=\operatorname{AAC}(\lambda)$ $=\operatorname{SAC}(\lambda)$ and (b) if AAC and SAC are constants, independent of wavelength $\lambda$, the wavelength-dependent part of EAC is the product of $\omega(\lambda)$ and the difference between SAC and $\mathrm{AAC}$ as shown in the second line of Eq. (2h).

In the Rayleigh regime, particle dimensions are small compared to the wavelength $\lambda$ resulting in a size parameter $x$ (i.e. for spherical particles, $x$ is the ratio of particle circumference and $\lambda$ ) of $x \ll 1$. It is well known that in the Rayleigh regime $\mathrm{SAC}_{\text {Ray }}=4$ (why is the sky blue?) and $\mathrm{AAC}_{\text {Ray }}=1$, under the assumption of wavelength independent refractive indices (Bohren and Huffman, 1998; Moosmüller and Arnott, 2009). Equation (2h) immediately yields the missing information on $\mathrm{EAC}_{\text {Ray }}$ as

$\operatorname{EAC}_{\text {Ray }}(x)=1+3 \omega(x)$,

where both $\mathrm{EAC}_{\mathrm{Ray}}$ and $\omega$ are written as functions of size parameter $x$, which incorporates both wavelength and particle diameter. In addition, in the Rayleigh regime $\omega$ can be expressed simply as function of size parameter $x$ and complex refractive index $m$ as (Bohren and Huffman, 1998; Moosmüller and Arnott, 2009)

$\omega(x)=\left[1+\frac{3}{2 x^{3}} \frac{\operatorname{IM}\left\{\frac{m^{2}-1}{m^{2}+2}\right\}}{\left|\frac{m^{2}-1}{m^{2}+2}\right|}\right]^{-1}$,

yielding a simple analytical expression for $\mathrm{EAC}_{\text {Ray }}$ as

$\operatorname{EAC}_{\text {Ray }}(x)=1+3\left[1+\frac{3}{2 x^{3}} \frac{\operatorname{IM}\left\{\frac{m^{2}-1}{m^{2}+2}\right\}}{\left|\frac{m^{2}-1}{m^{2}+2}\right|}\right]^{-1}$,

where IM stands for the imaginary part. This nicely complements the well-known constants for $\mathrm{SAC}_{\mathrm{Ray}}$ and $\mathrm{AAC}_{\mathrm{Ray}}$. 


\section{Generalization to two-wavelength Ångström coefficients}

As Eq. (2h) is written for single-wavelength Ångström coefficients and albedos, it is not a priori clear how to use it for two-wavelength Ångström coefficients, especially as no two-wavelength definitions of SSA and SSCA are in common use. However, using two-wavelength SSA and SSCA in Eq. (2h) and the two-wavelength definitions of AAC, SAC, and EAC given in Eq. (1b), the two-wavelength SSA $\omega\left(\lambda_{1}, \lambda_{2}\right)$ can be defined as

$$
\begin{aligned}
\omega\left(\lambda_{1}, \lambda_{2}\right) & =\frac{\operatorname{EAC}\left(\lambda_{1}, \lambda_{2}\right)-\operatorname{AAC}\left(\lambda_{1}, \lambda_{2}\right)}{\operatorname{SAC}\left(\lambda_{1}, \lambda_{2}\right)-\operatorname{AAC}\left(\lambda_{1}, \lambda_{2}\right)} \\
& =\left[1-\frac{\ln \left[\omega\left(\lambda_{1}\right)\right]-\ln \left[\omega\left(\lambda_{2}\right)\right]}{\ln \left[1-\omega\left(\lambda_{1}\right)\right]-\ln \left[1-\omega\left(\lambda_{2}\right)\right]}\right]^{-1} .
\end{aligned}
$$

Equation (3a) is well defined for the entire parameter space of $0 \leq \omega\left(\lambda_{1}\right) \leq 1$ and $0 \leq \omega\left(\lambda_{2}\right) \leq 1$. It essentially gives the two-wavelength SSA $\omega\left(\lambda_{1}, \lambda_{2}\right)$ as logarithmically weighted "average" of $\omega\left(\lambda_{1}\right)$ and $\omega\left(\lambda_{2}\right)$ and the two-wavelength SSCA $\varpi\left(\lambda_{1}, \lambda_{2}\right)$ can be defined equivalent to the single-wavelength definition of Eq. (2g) as

$\varpi\left(\lambda_{1}, \lambda_{2}\right)=1-\omega\left(\lambda_{1}, \lambda_{2}\right)$.

Note that the definition of the two-wavelength SSA $\omega\left(\lambda_{1}, \lambda_{2}\right)$ has a couple of symmetries, namely (a) symmetry around the line $\omega\left(\lambda_{1}\right)=\omega\left(\lambda_{2}\right)$, for which $\omega\left(\lambda_{1}, \lambda_{2}\right)=\omega\left(\lambda_{1}\right)=$ $\omega\left(\lambda_{2}\right)$, yielding the symmetry $\omega\left(\lambda_{1}, \lambda_{2}\right)=\omega\left(\lambda_{2}, \lambda_{1}\right)$ and (b) symmetry around the line $\omega\left(\lambda_{1}\right)+\omega\left(\lambda_{2}\right)=1$, for which $\omega\left(\lambda_{1}, \lambda_{2}\right)=0.5$, yielding the symmetry $\omega\left(\lambda_{1}, \lambda_{2}\right)=1-$ $\omega\left(1-\lambda_{1}, 1-\lambda_{2}\right)$. Related symmetries exist for SSCA.

Using Eqs. (3a, b) as definitions of two-wavelength SSA and SSCA, Eqs. (2h), (4d), and (5) can be used for twowavelength Ångström coefficients by replacing all occurrences of $(\lambda)$ with $\left(\lambda_{1}, \lambda_{2}\right)$, thereby yielding the explicit twowavelength $\operatorname{EAC}\left(\lambda_{1}, \lambda_{2}\right)$ (i.e. equivalent to Eq. $2 \mathrm{~h}$ ) as

$$
\begin{aligned}
& \operatorname{EAC}\left(\lambda_{1}, \lambda_{2}\right)=\operatorname{AAC}\left(\lambda_{1}, \lambda_{2}\right)+\omega\left(\lambda_{1}, \lambda_{2}\right)\left[\operatorname{SAC}\left(\lambda_{1}, \lambda_{2}\right)\right. \\
& \left.\quad-\operatorname{AAC}\left(\lambda_{1}, \lambda_{2}\right)\right]=\operatorname{AAC}\left(\lambda_{1}, \lambda_{2}\right) \\
& +\left[1-\frac{\ln \left[\omega\left(\lambda_{1}\right)\right]-\ln \left[\omega\left(\lambda_{2}\right)\right]}{\ln \left[1-\omega\left(\lambda_{1}\right)\right]-\ln \left[1-\omega\left(\lambda_{2}\right)\right]}\right]^{-1}\left[\operatorname{SAC}\left(\lambda_{1}, \lambda_{2}\right)\right. \\
& \left.-\operatorname{AAC}\left(\lambda_{1}, \lambda_{2}\right)\right] .
\end{aligned}
$$

\section{Single Scattering Albedo (SSA) Ångström coefficient SSAAC}

Inserting the definition of SSA $\omega$ from Eq. (2f), into the general definition of $\mathrm{AC}$ given by Eq. (1c) and using the quotient rule, the SSA Ångström coefficient SSAAC can be expressed as

$$
\begin{gathered}
\operatorname{SSAAC}(\lambda)=-\frac{\lambda}{\omega(\lambda)} \frac{d \omega(\lambda)}{d \lambda}=-\frac{\lambda}{\omega(\lambda)} \frac{d \frac{\beta(\lambda)}{\beta(\lambda)+\alpha(\lambda)}}{d \lambda} \\
=-\frac{\lambda}{\omega(\lambda)}\left[\frac{\frac{d \beta(\lambda)}{d \lambda}}{\beta(\lambda)+\alpha(\lambda)}-\beta(\lambda) \frac{\frac{d \beta(\lambda)}{d \lambda}+\frac{d \alpha(\lambda)}{d \lambda}}{(\beta(\lambda)+\alpha(\lambda))^{2}}\right] .
\end{gathered}
$$

In Eq. (4a), $d \alpha / d \lambda$ and $d \beta / d \lambda$ can be replaced using Eqs. (2c) and (2d), respectively, yielding

$$
\begin{array}{r}
\operatorname{SSAAC}(\lambda)=-\frac{\lambda}{\omega(\lambda)(\beta(\lambda)+\alpha(\lambda))}\left[-\frac{\beta(\lambda)}{\lambda} \operatorname{SAC}(\lambda)\right. \\
\left.+\frac{\beta(\lambda)}{\beta(\lambda)+\alpha(\lambda)}\left(\frac{\beta(\lambda)}{\lambda} \operatorname{SAC}(\lambda)+\frac{\alpha(\lambda)}{\lambda} \operatorname{AAC}(\lambda)\right)\right] .
\end{array}
$$

Some further rearrangement and use of the definition of SSA in Eq. (2f) yields

$$
\begin{aligned}
& \operatorname{SSAAC}(\lambda)=-[\operatorname{SAC}(\lambda)(\omega(\lambda)-1)+(1-\omega(\lambda)) \operatorname{AAC}(\lambda)] \\
& =\omega(\lambda)(\operatorname{AAC}(\lambda)-\operatorname{SAC}(\lambda))+(\operatorname{SAC}(\lambda)-\operatorname{AAC}(\lambda))(4 \mathrm{c})
\end{aligned}
$$

and finally reduces to the form

$\operatorname{SSAAC}(\lambda)=\varpi(\lambda)(\operatorname{SAC}(\lambda)-\operatorname{AAC}(\lambda))$.

The SSAAC equals the difference between SAC and AAC multiplied with the SSCA $\varpi$. Note that for two-wavelength Ångström coefficients, the two-wavelength definition of SSCA in Eqs. (3a, b) must be used.

\section{Combinations of equations}

Additional useful equations for SSAAC can be obtained by combining Eq. (4d) with Eq. (2h) yielding

$\operatorname{SSAAC}(\lambda)=\operatorname{SAC}(\lambda)-\operatorname{EAC}(\lambda)$.

and

$\operatorname{SSAAC}(\lambda)=(\operatorname{EAC}(\lambda)-\operatorname{AAC}(\lambda)) \frac{\varpi(\lambda)}{\omega(\lambda)}$.

In addition, with SSA and SSCA Ångström coefficients SSAAC and SSCAAC defined by Eq. (1c), their relationship can be directly obtained as

$\operatorname{SSCAAC}(\lambda)=\frac{-\omega(\lambda)}{\varpi(\lambda)} \operatorname{SSAAC}(\lambda)$

and combing Eq. (5c) with Eq. (5b) yields

$$
\operatorname{SSCAAC}(\lambda)=\operatorname{AAC}(\lambda)-\operatorname{EAC}(\lambda) \text {. }
$$

Again Eq. (5) can be used with two-wavelength Ångström coefficients, if the two-wavelength definitions of SSA and SSCA in Eqs. (3a, b) are employed where needed. 


\section{Conclusions}

Simple analytical relations have been developed connecting ACs for aerosol extinction, scattering, and absorption coefficients, and single scattering albedo. These relationships will be useful for performing comparisons and closure between different measurements of the wavelength-dependent aerosol optical properties parameterized in terms of ACs. They will be of special interest for ground-truthing of the wavelength dependence obtained from satellite aerosol optical depth measurements with that from ground-based and airborne measurements of scattering and absorption coefficients. Future work will include applications of these relationships to existing data of wavelength-dependent aerosol optics measurements.

\section{Appendix A}

\section{Symbols used}

$\begin{array}{ll}\text { Name } & \text { Symbol } \\ \text { Absorption coefficient } & \alpha \\ \text { Absorption Ångström coefficient } & \text { AAC } \\ \text { Ångström coefficient } & \text { AC } \\ \text { Complex refractive index } & m \\ \text { Extinction Ångström coefficient } & \text { EAC } \\ \text { Extinction coefficient } & \gamma \\ \text { Parameter } & p \\ \text { Scattering Ångström coefficient } & \text { SAC } \\ \text { Scattering coefficient } & \beta \\ \text { Single scattering albedo (SSA) Ångström } & \text { SSAAC } \\ \text { coefficient } & \\ \text { Single scattering albedo (SSA) } & \omega \\ \text { Single scattering co-albedo (SSCA) } & \text { SSCAAC } \\ \text { Angström coefficient } & \\ \text { Single scattering co-albedo (SSCA) } & \varpi \\ \text { Size parameter } & x \\ \text { Wavelength } & \lambda\end{array}$

Acknowledgements. This material is based upon work supported by NASA EPSCoR under Cooperative Agreement No. NNX10AR89A, by NASA ROSES under grant NNX11AB79G, by the National Science Foundation under Cooperative Support Agreement No. EPS-0814372 and under Major Research Instrumentation grant AGS-1040046, and by the Desert Research Institute.

Edited by: T. Kirchstetter

\section{References}

Ångström, A.: On the Atmospheric Transmission of Sun Radiation and on Dust in the Air, Geogr. Ann., 11, 156-166, 1929.

Bohren, C. F. and Huffman, D. R.: Absorption and Scattering of Light by Small Particles, Wiley, New York, xiv, 530 pp., 1998.

Dubovik, O. and King, M. D.: A Flexible Inversion Algorithm for Retrieval of Aerosol Optical Properties from Sun and Sky Radiance Measurements, J. Geophys. Res., 105, 20673-20696, 2000.
Dubovik, O., Holben, B. N., Kaufman, Y. J., Yamasoe, M., Smirnov, A., Tanré, D., and Slutsker, I.: Single-Scattering Albedo of Smoke Retrieved from the Sky Radiance and Solar Transmittance Measured from Ground, J. Geophys. Res., 103, 3190331923, 1998.

Eversole, J. D., Lin, H.-B., Huston, A. L., Campillo, A. J., Leung, P. T., Liu, S. Y., and Young, K.: High-Precision Identification of Morphology-Dependent Resonances in Optical Processes in Microdroplets, J. Opt. Soc. Am. B, 10, 1955-1968, 1993.

Fischer, E. V., Jaffe, D. A., Marley, N. A., Gaffney, J. S., and Marchany-Rivera, A.: Optical Properties of Aged Asian Aerosols Observed over the US Pacific Northwest, J. Geophys. Res., 115, D20209, doi:10.1029/2010JD013943, 2010.

Flowers, B. A., Dubey, M. K., Mazzoleni, C., Stone, E. A., Schauer, J. J., Kim, S.-W., and Yoon, S. C.: Optical-chemicalmicrophysical relationships and closure studies for mixed carbonaceous aerosols observed at Jeju Island; 3-laser photoacoustic spectrometer, particle sizing, and filter analysis, Atmos. Chem. Phys., 10, 10387-10398, doi:10.5194/acp-10-103872010, 2010.

Lewis, K., Arnott, W. P., Moosmüller, H., and Wold, C. E.: Strong Spectral Variation of Biomass Smoke Light Absorption and Single Scattering Albedo Observed with a Novel DualWavelength Photoacoustic Instrument, J. Geophys. Res., 113, D16203, doi:10.1029/2007JD009699, 2008.

Mishchenko, M. I., Cairns, B., Kopp, G., Schueler, C. F., Fafaul, B. A., Hansen, J. E., Hooker, R. J., Itchkawich, T., Maring, H. B., and Travis, L. D.: Accurate Monitoring of Terrestrial Aerosols and Total Solar Irradiance - Introducing the Glory Mission, B. Am. Meteorol. Soc., 88, 677-691, 2007.

Moosmüller, H. and Arnott, W. P.: Particle Optics in the Rayleigh Regime, J. Air Waste Manage. Assoc., 59, 1028-1031, 2009.

Moosmüller, H., Chakrabarty, R. K., and Arnott, W. P.: Aerosol Light Absorption and its Measurement: A Review, J. Quant. Spectrosc. R., 110, 844-878, 2009.

Moosmüller, H., Chakrabarty, R. K., Ehlers, K. M., and Arnott, W. P.: Absorption Ångström coefficient, brown carbon, and aerosols: basic concepts, bulk matter, and spherical particles, Atmos. Chem. Phys., 11, 1217-1225, doi:10.5194/acp-11-12172011, 2011.

Russell, P. B., Bergstrom, R. W., Shinozuka, Y., Clarke, A. D., DeCarlo, P. F., Jimenez, J. L., Livingston, J. M., Redemann, J., Dubovik, O., and Strawa, A.: Absorption Angstrom Exponent in AERONET and related data as an indicator of aerosol composition, Atmos. Chem. Phys., 10, 1155-1169, doi:10.5194/acp10-1155-2010, 2010.

Schuster, G. L., Dubovik, O., and Holben, B. N.: Angstrom Exponent and Bimodal Aerosol Size Distributions, J. Geophys. Res., 111, D07207, doi:10.1029/2005JD006328, 2006.

Virkkula, A., Ahlquist, N. C., Covert, D. S., Arnott, W. P., Sheridan, P. J., Quinn, P. K., and Coffman, D. J.: Modification, Calibration and a Field Test of an Instrument for Measuring Light Absorption by Particles, Aerosol Sci. Tech., 39, 68-83, 2005.

Zhu, L., Martins, J. V., and Remer, L. A.: Biomass Burning Aerosol Absorption Measurements with MODIS Using the Critical Reflectance Method, J. Geophys. Res., 116, D07202, doi:10.1029/2010JD015187, 2011. 